\title{
Single Feedback Regulation of the AC Voltage for High-Power Inverters under Stand-Alone Operation
}

\author{
Joseba Erdocia, Andoni Urtasun, Luis Marroyo \\ Public University of Navarre (UPNA) \\ Insititute of Smart Cities \\ Campus de Arrosadía \\ 31006 Pamplona, Spain \\ Email: ioseba.erdocia@unavarra.es
}

\section{Acknowledgements}

This work was supported by the Spanish State Research Agency (AEI) and FEDER-UE under grant DPI2016-80641-R and by the Public University of Navarre through a doctoral scholarship. The authors acknowledge the financial and continuous support of INGETEAM POWER TECHNOLOGY.

\section{Keywords}

«Active damping», «Regulators», «Three-phase system», «Harmonics», «Distributed power», «Frequency domain analysis», «Converter control»

\begin{abstract}
Energy-storage inverters under stand-alone operation must control the output voltage. However, existing methods for instantaneous voltage regulation are not suitable for high-power inverters due to their limited sampling frequency. To avoid this problem, a single feedback voltage loop with feedforward compensation is proposed in this paper, making it possible to actively damp the LCL filter resonance and thus facilitating the controller design. Simulation results demonstrate the fast reference tracking and the high-quality voltage obtained with non-linear loads.
\end{abstract}

\section{Introduction}

In recent years, distributed generation with renewable energy sources has gained strength as an alternative to fossil fuel generation. In this context, the use of inverters together with energy storage systems is getting attention as an option for stand-alone operation at places where there is no grid access or with low-quality grids. In these systems, an output voltage regulation is required in order to supply the loads.

For stand-alone inverters, a traditional approach for high-power inverters is based on regulating the RMS voltage instead of the instantaneous voltage [1], [2]. Since the feedback control follows a DC signal, a simple PI controller is able to accurately track the RMS reference. Nevertheless, its reply to unexpected load changes is especially slow, no active damping is provided and the voltage THD is strongly penalized with non-linear loads. To reduce voltage distortion, harmonic compensation techniques have been developed [3]. Although these methods make it possible to achieve an improvement in the THD, the implementation complexity is considerably increased.

For the purpose of solving these problems, some authors have considered instantaneous voltage regulation. In [4], the output voltage is controlled indirectly through a closed loop of the inductor current, where the reference is calculated employing the capacitor current and the current measured in the load. 
Although this approach ensures low voltage THD under non-linear loads, the load and capacitor currents need to be measured and thus additional sensors are required.

Another widespread solution is introducing cascaded controls loops, which consist of inner current and outer voltage loops. This method presents satisfactory dynamic features for low-power inverters [5]-[8]. However, for high-power inverters, which operate with low switching and sampling frequencies, it is not possible to decouple both loops and obtain acceptable dynamics for the voltage loop. As an alternative, a single voltage feedback loop is proposed in [9] to broaden the bandwidth, introducing a modified PID controller. In this system, the fast analog PID controller makes it possible to regulate the voltage with a crossover frequency over the resonance frequency of the LCL filter. Nevertheless, once again, for high-power inverters, this control implementation is unfeasible.

This paper presents an instantaneous voltage control for a 1.1 MVA inverter under stand-alone operation. The approach is also based on a single feedback loop, but including a feedforward voltage compensation, which actively damps the LCL filter resonance. As a result, it is possible to design a stable voltage regulation with a crossover frequency below the resonance frequency, being thus suitable for high-power inverters. In the paper, it is shown that this method makes it possible to achieve a fast and accurate voltage tracking and a high quality voltage with non-linear loads. The details of this method are discussed in section II, the simulation results are shown in section III, and the conclusions are drawn in section IV.

\section{AC Voltage regulation}

The system considered in this paper is shown in Figure 1. It consists of an energy storage system, a bus capacitor, a three-phase inverter, an LC output filter and a transformer connected to the loads, which include linear as well as non-linear loads. In stand-alone mode, the inverter works as a voltage source, controlling the output phase voltage.

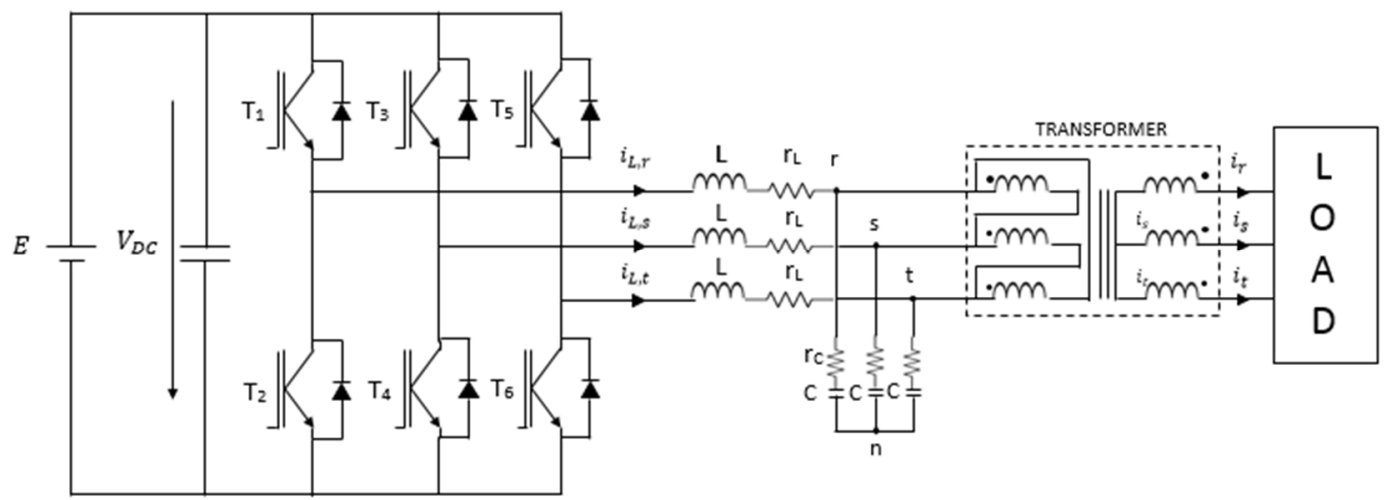

Fig. 1. Three-phase inverter, under stand-alone operation.

Table I shows the parameters considered for the case study, where the transformer values are given for equivalent star configuration.

Table I Parameters of the system

\begin{tabular}{c|c} 
DC source voltage & $700 \mathrm{~V}$ \\
\hline Inverter inductance, $\mathrm{L}$ & $70 \mu \mathrm{H}$ \\
\hline Inverter inductance parasitic resistance, $\mathrm{r}_{\mathrm{L}}$ & $0.13 \mathrm{~m} \Omega$ \\
\hline Inverter capacitance, $\mathrm{C}$ & $780 \mu \mathrm{F}$ \\
\hline Inverter capacitance parasitic resistance, $\mathrm{r}_{\mathrm{C}}$ & $0.65 \mathrm{~m} \Omega$ \\
\hline Transformer inductance, $\mathrm{L}_{\mathrm{tr}}$ & $31 \mu \mathrm{H}$
\end{tabular}

\begin{tabular}{c|c} 
Transformer resistance, $\mathrm{r}_{\mathrm{tr}}$ & $1.83 \mathrm{~m} \Omega$ \\
\hline Phase RMS voltage & $230 \mathrm{~V}$ \\
\hline Inverter rated power & $1.1 \mathrm{MVA}$ \\
\hline Switching frequency, $\mathrm{f}_{\mathrm{sw}}$ & $3 \mathrm{kHz}$ \\
\hline Sampling frequency, $\mathrm{f}_{\mathrm{s}}$ & $6 \mathrm{kHz}$ \\
\hline Voltage filter cutoff frequency, $\mathrm{f}_{\mathrm{Hv}}$ & $2680 \mathrm{~Hz}$
\end{tabular}


A three-phase balanced system is provided by the inverter. As a result, since two degrees of freedom remain, only two voltages are directly regulated, namely $v_{r n}$ and $v_{s n}$. In addition, third harmonic injection is used to reduce the minimum DC voltage required.

Figure 2 shows the control scheme for the phase voltage regulation, where $v_{r n}^{*}$ represents the instantaneous phase voltage reference, $v_{r n, f}$ the measured phase voltage, $v_{L, r e f}$ the inductor voltage reference, $m_{r}$ the modulation signal, $C_{v}$ the voltage controller, $D_{s}$ the digital sampling, $H_{v}$ the voltage filter and $\mathrm{P}$ the system plant. As can be observed, a feedforward compensation of the controlled voltage is included.

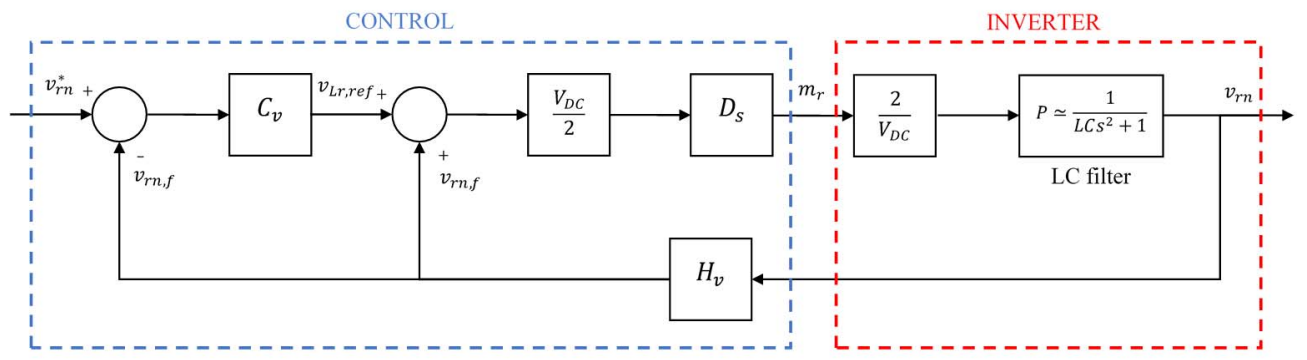

Fig. 2. Three-phase inverter, under stand-alone operation.

The design of the voltage regulator has been carried out at no-load condition, since it is the most restrictive situation in terms of control stability. In this case, the system plant can be obtained as (1), where the approximation with $r_{L}=r_{C}=0$ is shown for clarity purposes.

$$
P=\frac{C \cdot r_{C} \cdot s+1}{C \cdot L \cdot s^{2}+C \cdot\left(r_{L}+r_{C}\right) \cdot s+1} \simeq \frac{1}{L \cdot C \cdot s^{2}+1}
$$

Due to the included voltage feedforward term (see Fig. 2), the equivalent plant seen by the controller, $P_{\text {eq }}$, can be obtained as

$$
P_{e q}=\frac{v_{L r, r e f}}{v_{r n}}=\frac{D_{s} \cdot P}{1-D_{s} \cdot P \cdot H_{v}},
$$

where a perfect DC voltage compensation is assumed.

Figure 3 shows the Bode plots of both plants $\mathrm{P}$ and $\mathrm{P}_{\text {eq. }}$. It is observed that thanks to the feedforward term, the LC filter resonance is considerably damped, thus making it possible to control the system.

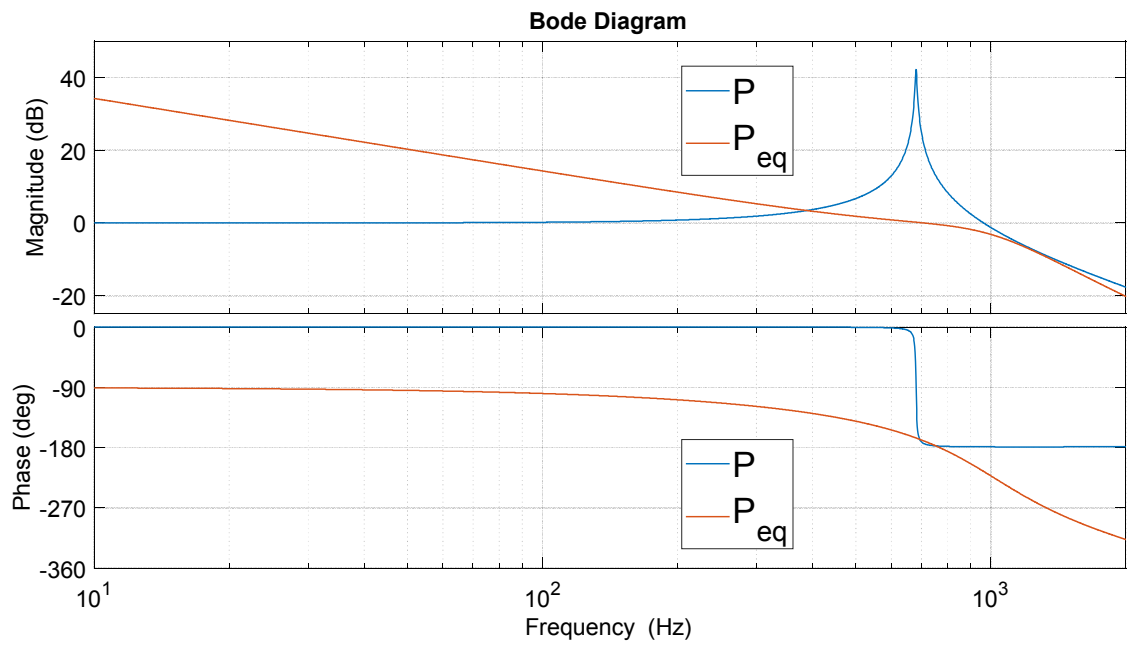

Fig. 3. Bode plots of $\mathrm{P}$ and Peq. 
In order to ensure fast and accurate voltage tracking, as well as to compensate voltage harmonics when the system is working with non-linear loads, the following proportional-resonant (PR) controller is proposed:

$$
\begin{aligned}
C_{v}(s)=K_{p}+ & \sum_{h=1,5,7} K_{h, r} \cdot \frac{s \cdot \cos \left(\varphi_{h}\right)-h \cdot \omega_{1} \cdot \sin \left(\varphi_{h}\right)}{s^{2}+\left(h \cdot \omega_{1}\right)^{2}} \\
& +\sum_{h=11,13} \frac{K_{h, r}}{h \cdot \omega_{1}} \cdot \frac{s \cdot\left(s \cdot \cos \left(\varphi_{h}\right)-h \cdot \omega_{1} \cdot \sin \left(\varphi_{h}\right)\right)}{s^{2}+\left(h \cdot \omega_{1}\right)^{2}}
\end{aligned}
$$

where $\mathrm{h}$ represents the harmonic order, $\varphi_{h}$ the leading phase for each harmonic, $\omega_{1}$ the frequency of the fundamental, $K_{h, r}$ the resonant gain for each harmonic and $K_{p}$ proportional gain. The latter gain and the leading angles have been selected in a way that the compensated open loop transfer function has a crossover frequency $\omega_{c}$ equal to $280 \mathrm{~Hz}$, all phase margins higher than $45^{\circ}$ and sensitivity peak higher than 0.5 . The resonant term introduced to harmonics $11^{\text {th }}$ and $13^{\text {th }}$ has an additional zero since a phase lead higher than $90^{\circ}$ is required to fulfill the mentioned stability margins [10]. In addition, the resonant gains have been chosen to ensure a perfect tracking and an adequate voltage harmonic compensation. Figure 4 represents the compensated open loop, where the system stability can be verified applying the Generalized Bode Criterion proposed in [11]. The regulator parameters, which have been chosen for controlling the system under study, are shown in Table II.

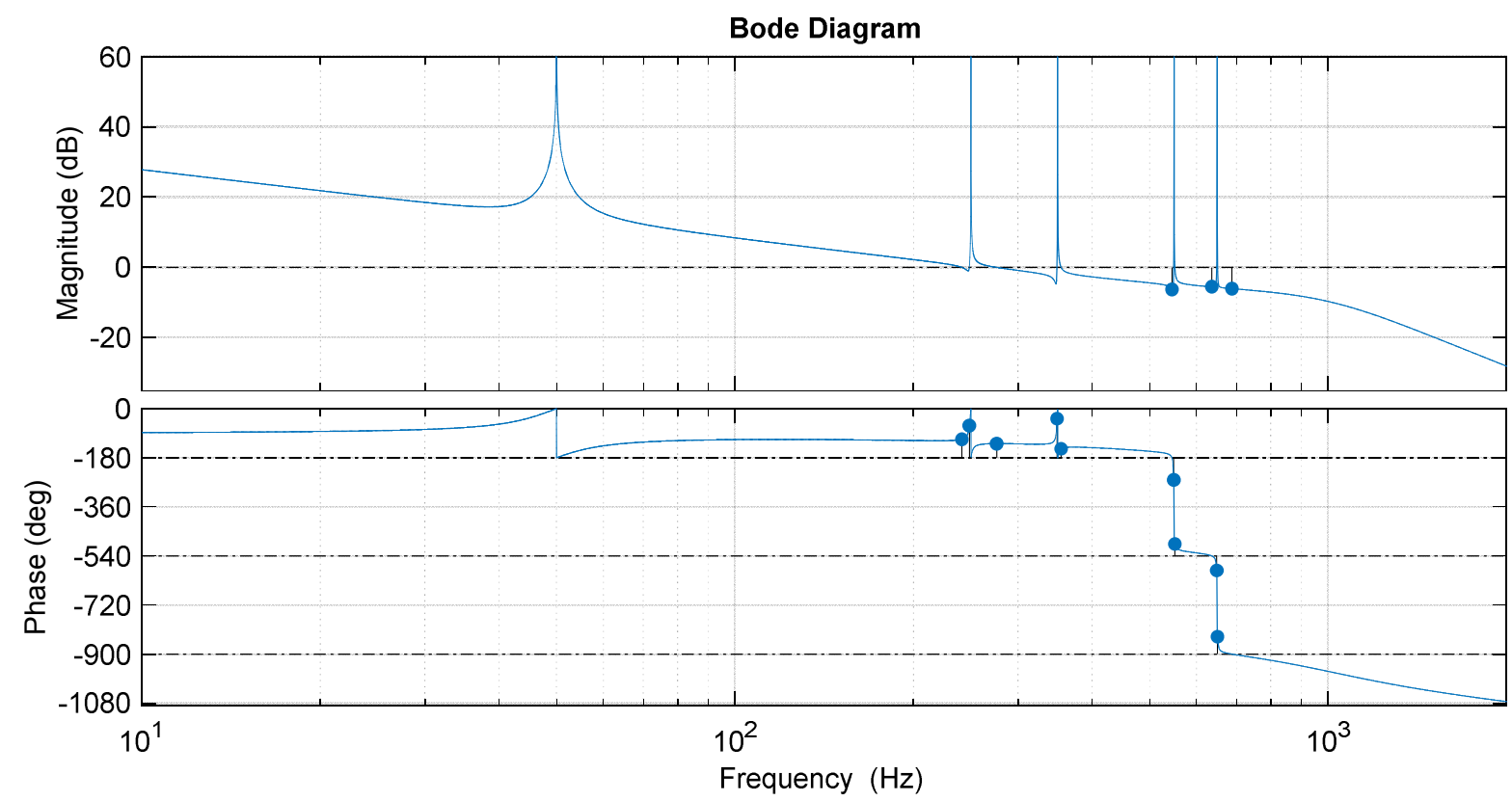

Fig. 4. Bode plots of $\mathrm{P}$ and Peq.

Table II Voltage controller parameters.

\begin{tabular}{ccccc} 
Parameter & Value & & Parameter & Value \\
\cline { 1 - 2 } \cline { 5 - 6 } $\mathrm{K}_{\mathrm{p}}$ & 0.5 & & & \\
$\mathrm{~K}_{1, \mathrm{r}}$ & 50 & & $\varphi_{1}$ & $6^{\circ}$ \\
$\mathrm{K}_{5, \mathrm{r}}$ & 10 & & $\varphi_{5}$ & $30^{\circ}$ \\
$\mathrm{K}_{7, \mathrm{r}}$ & 10 & & $\varphi_{7}$ & $40^{\circ}$ \\
$\mathrm{K}_{11, \mathrm{r}}$ & 10 & & $\varphi_{11}$ & $50^{\circ}$ \\
$\mathrm{K}_{13, \mathrm{r}}$ & 10 & & $\varphi_{13}$ & $90^{\circ}$ \\
\hline
\end{tabular}




\section{Results}

In this section, two voltage control strategies are compared by simulation results. On the one hand, the traditional control method, which is based on regulating the RMS voltage including harmonic compensation, is considered. This strategy requires additional damping so as to stabilize the harmonic compensation. Therefore, as it is carried out in [3], a $34 \mathrm{~m} \Omega$ resistor is added in series with the capacitor, providing passive damping to the system. Although this has permitted to implement $5^{\text {th }}$ and $7^{\text {th }}$ harmonics cancellation, the compensation of higher-order harmonics remains unfeasible and it is not included.

On the other hand, the method proposed in section II is implemented. This strategy is designed so that the phase voltages $v_{r n}, v_{s n}$ and $v_{t n}$ track the selected reference for any type of load, and maintain and recover rapidly the desired value under load variations. In this case, an additional resistor does not need to be included, since active damping is provided by the feedforward compensation.

Both strategies are tested by using the simulation software PSIM. The system under study is composed by an ideal DC voltage source, a three-phase inverter, an output LC filter, and a transformer connected to the loads.

In the first simulation, the control behavior under load variations is studied. Figure 5 and 6 shows the results obtained for the traditional and proposed strategy, respectively, after an abrupt load disconnection of $500 \mathrm{kVA}$ with a power factor equal to 0.8 .

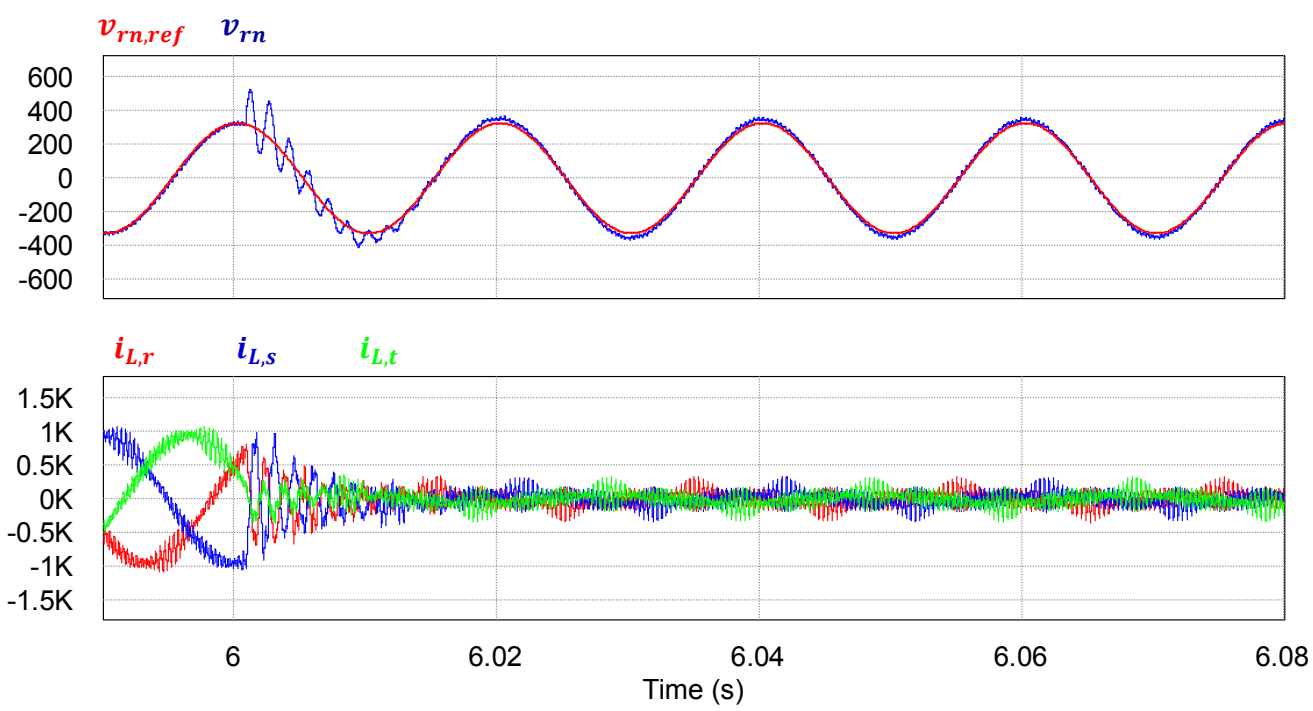

Fig. 5. Simulation results for a load disconnection with RMS voltage control strategy

Figure 5 shows that it takes much more than 4 cycles, specifically around $400 \mathrm{~ms}$, that the output voltage recovers an accurate tracking due to the slowness of the RMS voltage loop control. On the contrary, as can be observed in Figure 6, the proposed voltage control recovers the perfect tracking in less than $60 \mathrm{~ms}$. Moreover, although no damping resistor has been included, it is clear that the proposed method provides much better damping. 


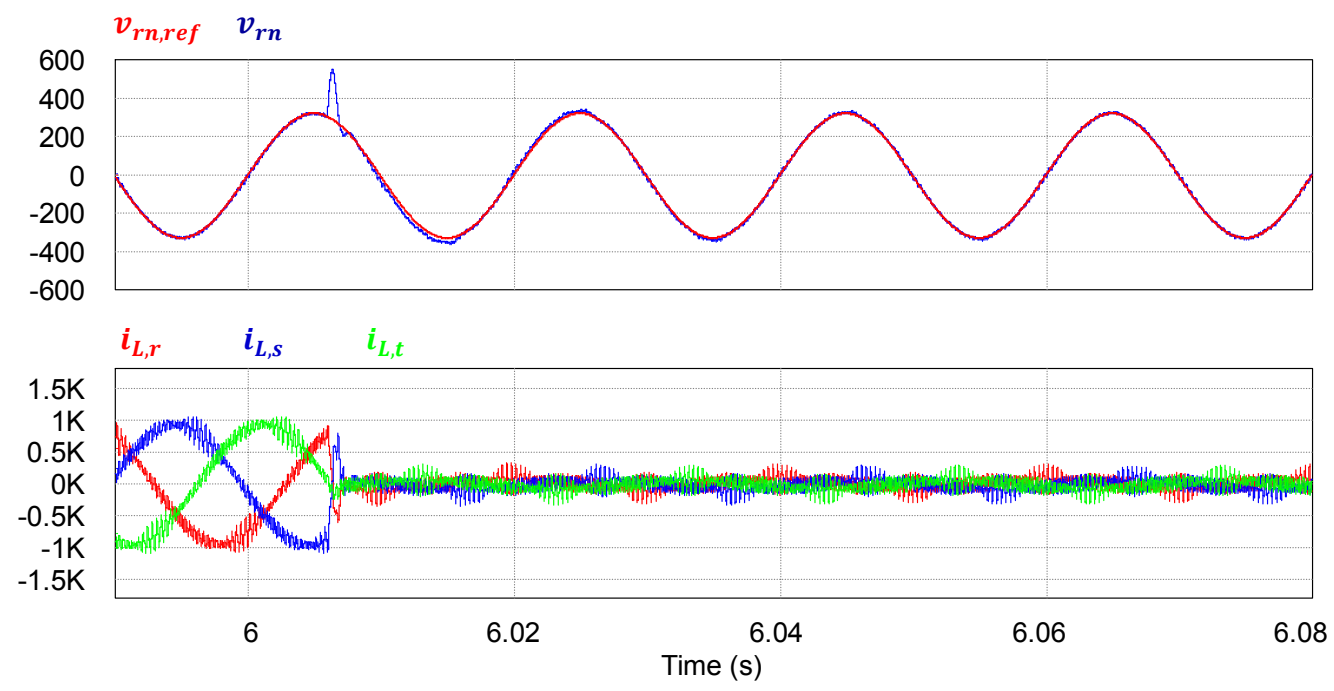

Fig. 6. Simulation results for a load disconnection with the proposed voltage control strategy.

In the second simulation, the steady-state response of both controls when operating with non-linear loads is analyzed. In this case, the starting of a $500 \mathrm{kVA}$ induction motor through a thyristor-based starter is modelled in PSIM. For this situation, the simulation results for the traditional and proposed controls are shown in Figure 7 and Figure 8, respectively, both in time and frequency domains.

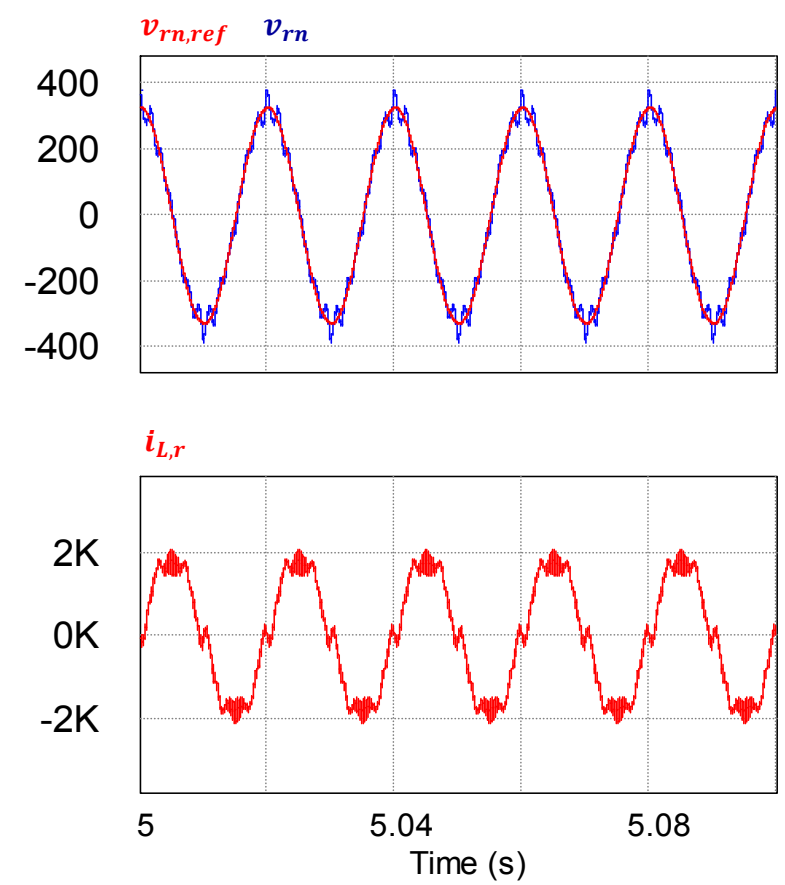

(a)
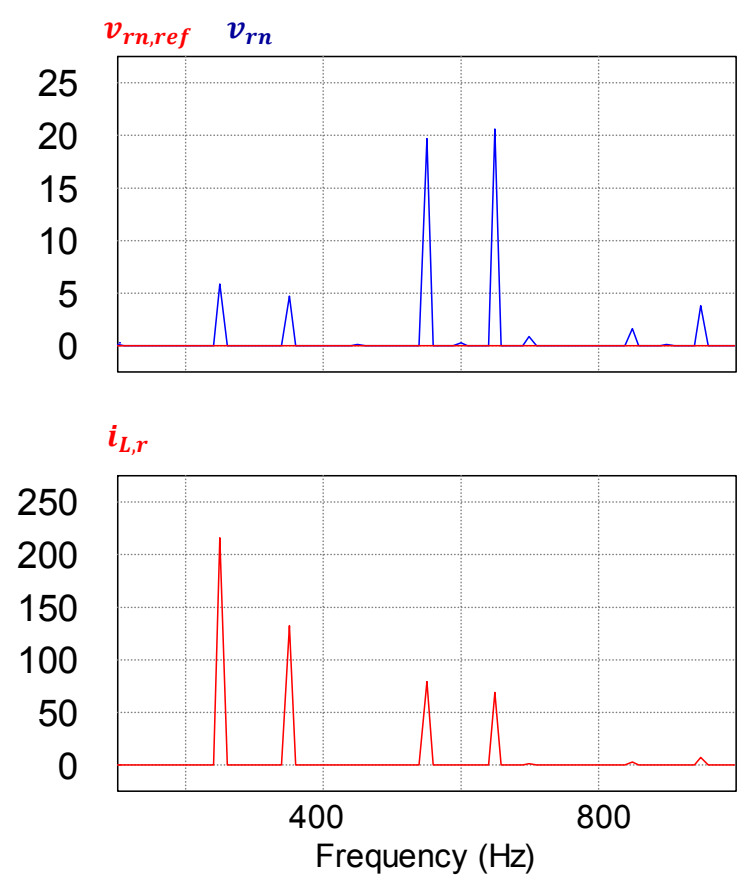

(b)

Fig. 7. Simulation results with non-linear load with RMS voltage strategy control. 

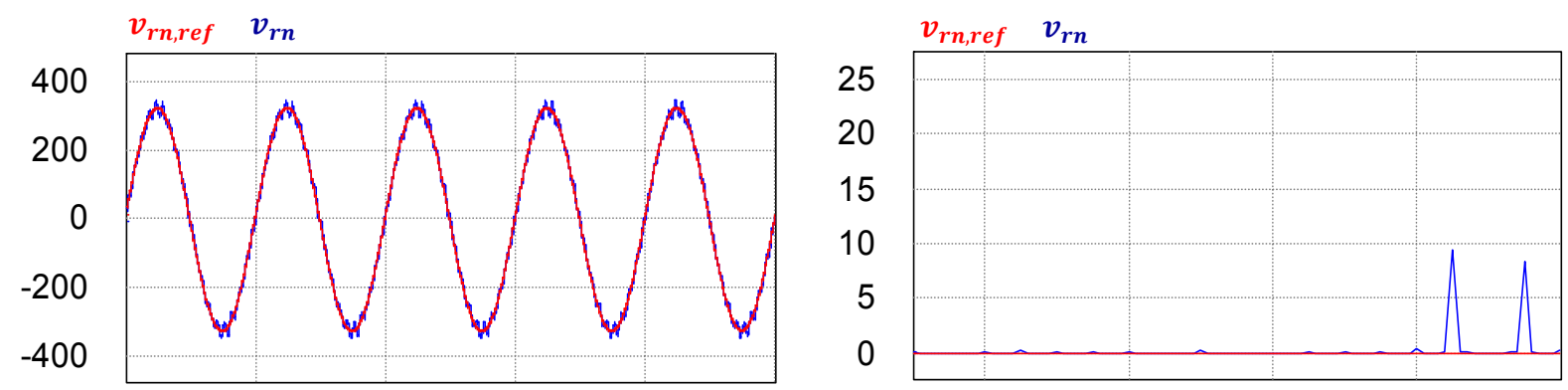

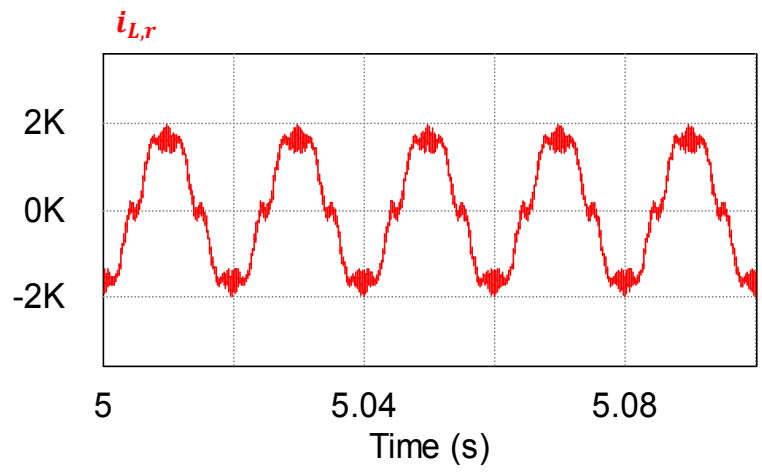

(a)

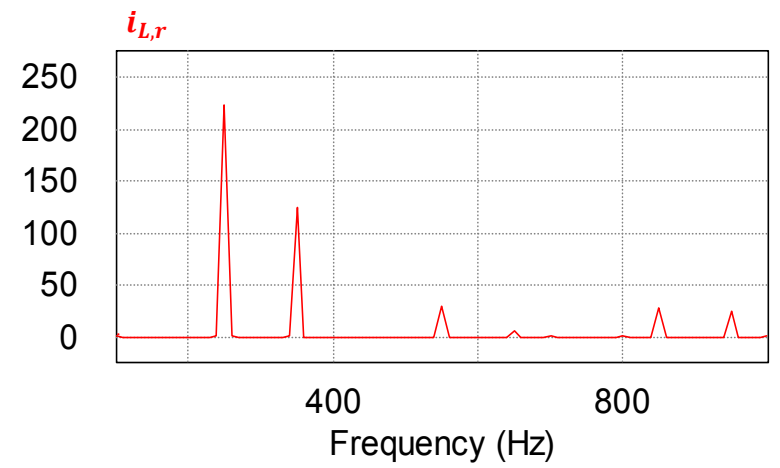

(b)

Fig. 8. Simulation results with non-linear load with the proposed voltage control strategy.

As can be observed in Fig.7 (a) and Fig.8 (a), the inverter is able in both cases to supply the large current harmonics required by the load, but the system working under the proposed strategy provides an output voltage of higher quality. More precisely, it can be observed in Fig.7 (b) that, for the traditional control, the voltage harmonics at 250 and $350 \mathrm{~Hz}$ are only partially removed. Moreover, harmonics at higher frequencies remain, since its cancellation cannot be implemented due to the mentioned stability problems. As a consequence, a voltage THD of $9.7 \%$ is obtained in this case. On the contrary, Fig.8 (b) shows how the voltage harmonics at $250,350,550$ and $650 \mathrm{~Hz}$ are completely rejected thanks to the proposed regulation. However, due to the limited sampling frequency of high power inverters, it is not possible to reject the harmonics at frequencies over $850 \mathrm{~Hz}$. In any case, since the latter harmonics are already small, the voltage THD obtained is greatly improved to $4 \%$ under the same negative load scenario.

\section{Conclusions}

This paper proposes an output voltage regulation for inverters under stand-alone operation. Firstly, a voltage feedforward compensation is introduced in order to damp the LC filter resonance, which makes it possible to stabilize the single feedback control loop for high-power inverters. Then, a PR controller is implemented to ensure a perfect voltage tracking as well as to reject the load harmonics. Furthermore, the proposed controller permits to obtain a rapid and damped response after an abrupt load disconnection. Simulation results have been reported to validate the proposed control approach, showing an adequate response under negative load scenarios. Besides, the superior behavior of the presented strategy has been demonstrated by comparison with the traditional control. 


\section{References}

[1] Y. Sozer and D. A. Torrey, "Modeling and control of utility interactive inverters," IEEE Trans. Power Electron., vol. 24, no. 11, pp. 2475-2483, 2009.

[2] P. Varela, D. Meneses, O. Garcia, J. A. Oliver, P. Alou, and J. A. Cobos, "Current mode with RMS voltage and offset control loops for a single-phase aircraft inverter suitable for parallel and 3-phase operation modes," IEEE Energy Convers. Congr. Expo. Energy Convers. Innov. A Clean Energy Futur. ECCE 2011, Proc., no. Vmc, pp. 2562-2567, 2011.

[3] D. Arricibita, P. Sanchis, R. Gonzalez, and L. Marroyo, "Impedance Emulation for Voltage Harmonic Compensation in PWM Stand-Alone Inverters," IEEE Trans. Energy Convers., vol. 32, no. 4, pp. 13351344, 2017.

[4] S. Mukherjee, P. Shamsi, and M. Ferdowsi, "Indirect voltage control of a stand-alone inverter," Conf. Proc. - IEEE Appl. Power Electron. Conf. Expo. - APEC, no. 3, pp. 3451-3455, 2017.

[5] N. Mazloum, O. Keikha, M. Yaghoubi, and F. Tahami, "A fast and cost-effective control of a three-phase stand-alone inverter," 8th Power Electron. Drive Syst. Technol. Conf. PEDSTC 2017, no. Pedstc, pp. 6772, 2017.

[6] B. J. Byen, J. M. Choe, and G. H. Choe, "High-performance voltage controller design based on capacitor current control model for stand-alone inverters," J. Electr. Eng. Technol., vol. 10, no. 4, pp. 1636-1646, 2015.

[7] F. De Bosio, M. Pastorelli, L. A. De Souza Ribeiro, F. D. Freijedo, and J. M. Guerrero, "Effect of state feedback coupling on the transient performance of voltage source inverters with LC filter," 2016 18th Eur. Conf. Power Electron. Appl. EPE 2016 ECCE Eur., 2016.

[8] Q. Lei, F. Z. Peng, and S. Yang, "Multiloop control method for high-performance microgrid inverter through load voltage and current decoupling with only output voltage feedback," IEEE Trans. Power Electron., vol. 26, no. 3, pp. 953-960, 2011.

[9] J. M. Guerrero, L. de Vicuna, J. Matas, M. Castilla, and J. Miret, "Output Impedance Design of ParallelConnected UPS Inverters With Wireless Load-Sharing Control," IEEE Trans. Ind. Electron., vol. 52, no. 4, pp. 1126-1135, 2005.

[10] A. G. Yepes, F. D. Freijedo, J. Doval-Gandoy, O. Lopez, J. Malvar, and P. Fernandez-Comesana, "Effects of Discretization Methods on the Performance of Resonant Controllers (vol 25, pg 1692, 2010)," IEEE Trans. Power Electron., vol. 27, no. 12, p. 4976, 2012.

[11] D. Lumbreras, E. L. Barrios, A. Urtasun, A. Ursua, L. Marroyo, and P. Sanchis, "On the Stability of Advanced Power Electronic Converters: the Generalized Bode Criterion," IEEE Trans. Power Electron., vol. PP, no. c, pp. 1-1, 2018. 